\title{
Water-oil metal partitioning and Re- Os geochronology of hydrocarbons: Implications for basinal systems
}

\author{
N. C. Hurtig ${ }^{1,2,3}$, H. J. Stein ${ }^{2,4}$, J. L. HANnAH ${ }^{2,4}$
}

${ }^{1}$ Dept. of Geology and Geological Engineering, Colorado School of Mines, Golden 80401, CO, USA

${ }^{2}$ AIRIE Program, Colorado State University, Fort Collins 80523-1482, CO, USA

${ }^{3}$ Dept. of Earth and Environmental Science, New Mexico

Tech, Socorro 87801, NM, USA

${ }^{4}$ Institute of Geosciences, University of Oslo, 0315, Norway

Basinal brines occur in the same stratigraphic intervals that host petroleum reservoirs, thus interaction of these two phases is plausible. We argue that trace metals with different chemical properties ultimately fractionate across the water-oil interface and become variably enriched or depleted in petroleum. Therefore, trace metal signatures in hydrocarbons might hold important information about migration pathways and water-oil interaction. Further, trace metal signatures in hydrocarbons could be key to understanding and linking hydrocarbon migration to sedimentary-hosted ore deposits, which often occur along the same structural features and permeability networks as petroleum reservoirs.

Here, we experimentally determine the fundamental controls on trace metal (including $\mathrm{Cd}, \mathrm{Co}, \mathrm{U}, \mathrm{As}, \mathrm{Ag}, \mathrm{Ni}$, Mo, and V) fractionation during water-oil interaction. The behavior of Re and Os during water-oil interaction is of special interest, because the Re-Os geochronometer is invaluable for directly determining the timing of formation of crude oils and their source materials.

Results show that Re and Os fractionate across the water-oil interface with Os preferentially partitioning into the oils over Re. We further establish that the prerequisites for Re-Os geochronology are maintained during Re and Os transfer from aqueous solutions to oils, proving that wateroil interaction can potentially set the Re-Os geochronological clock in petroleum systems. In general, trace metal behavior is highly variable with preferential partitioning of some elements into the aqueous solution (i.e., $\mathrm{Ba}, \mathrm{Ag}$ ) and retention and/or enrichment of other elements in the oil (i.e., Mo, U, Os, Re).

These novel data can be linked to process-oriented formation models and provide new tools to better understand, date and explore for both petroleum and sedimentary-hosted ore deposits. 